9.Наказ Державної служби України з питань праці «Про затвердження Покажчика нормативно-правових актів з охорони праці» від 15 січня 2018 року № 9 [Електронний peсурс]. - Режим доступу: https://zakon.rada.gov.ua/rada/show/v0009880-18; Nakaz Dierzhavnoi sluzhby z pytan pratsi «Pro zatverdzhiennia Pokazchika normatyvno-pravovyrh aktiv z okhorony pratsi» vid 15 sichnia 2018 roku № 9.

\title{
T. Vakhonieva
}

\section{LEGAL NATURE AND THE VALUE OF TECHNOLOGICAL DISCIPLINE IN LABOR LAW}

In the article the concept of technological discipline is investigated, its characteristic features and main components are determined. As a result of the research, various aspects of the concept of "discipline of labor" are considered and the peculiarities of the legal regulation of the technological process of production are analyzed. The basic normative acts containing the technical and legal norms are singled out, and the peculiarities of legal responsibility for violation of technological discipline in the context of labor discipline are established.

Key words: discipline of labor, technological discipline, industrial discipline, labor discipline, technological process, technical norms.

Стаття надійшла до редакції 20.05.2019 p.

УДК $340.1+378.4$

\section{Н. Л. Шелухин}

\section{О НАУЧНЫХ КОНФЕРЕНЦИЯХ В ОБЛАСТИ ПРАВА И НЕ ТОЛЬКО}

В статье рассматриваются вопросы проведения научных конференций в области юриспрудениии. Рассматривается классификаџия научных конференций, основные цели их проведения, выделяются основные этапы их проведения. Обращается внимание на проведение псевдонаучных конференций, приводятся и раскрываются их признаки. Вносятся предложения об унификачии требований к проведению научных конференций, а так же их проведения только под эгидою Академии юридических наук Украиньл

Ключевые слова: научная конференция, классификациия конференций, цеели и задачи конференций, Академия правовых наук Украины, псевдонаучные конференции, единая электронная библиотека материалов конференций.

DOI 10.34079/2226-3047-2019-9-17-72-79

Ежегодно в Украине в области юриспруденции проводятся сотни конференций, в названии которых присутствует слово «научная». Их организаторами выступают университеты и другие высшие учебные заведения, научные заведения и исследовательские центры, общественные организации и объединения, органы власти и местного самоуправления, министерства и ведомства, промышленные предприятия и объединения и т.д. В работе этих конференций принимают участие физические и юридические лица Украины и зарубежных стран, международные организации и фонды различной направленности. Финансирование этих конференций происходит за 
счет организаторов либо за счет участников. Среди громадного массива конференционных тематик сложно составить мнение о научном уровне конференции и определится с личным либо дистанционным участием в ее работе. Зачастую необходимо предварительное наведение справок о персональном участии конкретных ученых, тематики основных докладов и издании материалов конференции.

В связи с этим автор выносит на рассмотрение научной общественности свои рассуждения о таком методе научно-исследовательской деятельности как научная конференция, подходах к ее организации, целей и задачах проведения и уровня научности

Устоявшееся понятие научной конференции (англ. academic conference) как формы организации научной деятельности, я думаю, что никто оспаривать не будет. Процедуре проведения научных конференций, их планированию и эффективности проведения посвящено ряд научных работ различного уровня. Это, например, статьи: В.А. Балабан; М.В. Глаголева и Е.Д. Лапшиной; Н.Я. Головецкого, Л.Н. Мирошниченко и С.В. Колесниковой; Т.А. Дуденковой; О.А. Ерёмченко; Т.С. Королевой, И.А. Васильева и И.О. Торжкова и др. [1-6]. Причем рассмотрению подлежали как различные стадии и этапы проведения конференций, так и предпринималось попытка разработки критериев эффективности научных конференций. Если же проанализировать авторов по их научной принадлежности, то в основном это педагогический персонал высших учебных заведений. В связи с этим научные конференции рассматриваются как одна из форм учебно-методической работы.

Е.В. Павель и Е.В. Банная в статье «О результативности университетских научных конференций» приводят индикаторы для анализа; состава участников конференции и ее коммуникативной составляющей, финансовой составляющей научной конференции, значимости конференции для университета, научной результативности (различного рода публикации, полученные приглашения на другие конференции, заключенные договора на совместную научную деятельность и т. д.). Основным же результатом проведения конференции авторы видят улучшение академической репутации ВУЗа [7]. Это же мнения придерживаются и ряд других исследователей. На наш взгляд, предлагаемый авторами критерий носит не научный, а административно-организационный характер.

Другая группа ученых педагогов считает, что наиболее эффективно научные конференции выступают в качестве элемента подготовки студентов, организации их проектной работы и профессионального развития [8-10].

Третьи, при проведении научных конференций, ставят во главу угла эффективность научных коммуникаций $[1,11]$.

Не вступая в полемику с авторами вышеприведенных работ, считаем необходимым выразить свой взгляд на организацию и проведение научных конференций, причем конференций, проводимых по правовой тематике. Сразу же обращаем внимание на специфику обсуждаемых правовых проблем. Это, прежде всего, проблемы, связанные с:

- теоретическими исследованиями в области права,

- обсуждением и предложениями по усовершенствованию действующих нормативно-правовых актов,

- правоприменительной деятельностью.

В рамках данной статьи мы не рассматриваем;

- студенческие научные конференции, которые собственно являются продолжение образовательной деятельности и выполняют учебно-исследовательскую функцию при 
подготовке будущих юристов;

- коммерческие конференции на правовую тематику, проводимые в основном негосударственными организациями с целью получения финансовых средств;

- конференции, финансируемые грантами и фондами иностранных и международных организаций, зачастую носящие политический характер и проходящие по тематике, определенной этими фондами.

К универсальным целям любой правовой (и не только) конференции относятся:

- установлений новых и укрепление состоявшихся связей среди участников конференции; неформальное общение участников, которое способствует налаживанию контактов между учеными и способствует, в дальнейшем, совместной научной деятельности. Как показывает опыт, именно неформальное общение в ученой среде, способствует комплексным исследованиям с наивысшим уровнем эффективности полученных результатов.

- обмен опытом, информацией и мнениями о практике и тенденциях развития нормативно-правовой базы; взглядами на стоящую проблему, зафиксированными документально. Огромным преимуществом является непосредственно реальное общение заинтересованных участников, а не виртуальная переписка.

Профиль работы и эффективность проведения любой конференции в области права определяется, прежде всего, квалификацией ее участников и целями, преследованными организаторами проведения научного форума.

По тематике научные конференции делятся на специализированные (т.е. посвященные какой-либо отдельной тематике или отрасли права) и конференции широкой тематики, охватывающие разносторонние вопросы. Причем здесь же необходимо отметить, что в основном специализированные конференции по праву проводят либо профильные юридические высшие учебные заведения, либо университеты, имеющие научный потенциал, традиции преподавания и сложившиеся научные правовые школы: Одесская юридическая академия, Харьковский юридический университет им. Я. Мудрого, Львовский университет, Академия МВД Украины, Киевский университет им. Т. Шевченко. Например: «Приоритетные направления развития аграрного законодательства и права в современных условиях» «Актуальные проблемы судебного права», «Философия и право», «Тенденции развития науки трудового права и права социального обеспечения».

По цели проведения научные конференции в области права можно условно классифицировать на: теоретические, практические, научно-практические, названия и сущность названия и сущность которых определяются профилем и направлением деятельности участников - научно-исследовательская либо практическая деятельность.

Разновидностью вышеуказанных видов научных конференций являются конференции событийные. К событийным конференциям, на наш взгляд, необходимо отнести конференции, посвященные различным событиям:

юбилеям ВУЗов, факультетов, кафедр:

- юбилейная LXXV научная конференция профессорско-преподавательского состава, аспирантов, студентов и сотрудников структурных подразделений университета, посвященная 75-летию со дня основания Национального транспортного университета. 5-17 мая 2019;

- юбилейная XX Международная научно-практическая конференция «Человек, культура, техника в новом тысячелетии», посвященная 20-летию гуманитарного факультета Национального аэрокосмического университета им. Н. Е. Жуковского. «Харьковский авиационный институт». 23-24 апреля 2019 год;

- международная научная конференция «Современная криминология: 
достижения, проблемы, перспективы», посвященная 50-летию со дня основания кафедры криминологии и уголовно-исполнительного права Национального юридического университет им. Ярослава Мудрого. 9 декабря 2016.

памяти выдающихся ученых или общественных деятелей:

- «Проблемы гражданского права и процесса» научно-практическая конференция, посвященная памяти Александра Анатольевича Пушкина м. Харьков 25 мая 2018;

- «Юлиан Целевич - украинский историк и общественный деятель (1843-1892 гг.). К 175-летию со дня рождения ». Прикарпатский национальный университет им. В. Стефаника. 22 марта 2018.

каким-либо выдающимся событиям или фактам, имеющим большой общественный резонанс:

- международная научно-практическая конференция «Соборность Украины: правовое измерение», посвященная 100-летию Акта Злуки УНР и ЗУНР 22 января 1919 года. Киевский национальный университет имени Тараса Шевченко. 29 ноября 2018:

- всеукраинская научная историко-краеведческая конференция «Прошлое и современное Волыни и Полесья. Ковель и Ковельщина в украинской и европейской истории». Посвящена 27-й годовщине независимости Украины, 100-й годовщины Украинской революции и 500-й годовщины предоставления Ковелю Магдебургского права. 22 октября 2018.

Целью теоретических, практических, научно-практических научных конференций ставится возможность обсуждения теоретических и практических вопросов права и правоприменения, дискуссии по проблемным вопросам права и правотворческой деятельности, обмен опытом, укрепление связей между научными и практическими работниками, апробация материалов исследования и т.д.

При планировании научных конференций в смету их проведения закладываются средства на приглашение ведущих специалистов из Украины и других стран по тематике конференций, на издание материалов конференции и их рассылку, проведение ознакомительной экскурсии по месту расположения принимающей стороны и т.д. Финансирование проведения таких научных конференций берут на себя университеты, государство или международные организации.

Решения этих научных конференций доводятся до органов и организаций, заинтересованных в разработке обсужденной тематики, материалы издаются сборником с присвоением ISBN и рассылаются в крупнейшие профильные библиотеки, учебные и научные учреждения. Все вышесказанное относится к действительно научным, престижным конференциям, на которых решаются теоретические и практические задачи в области юриспруденции*.

Проблемой этих конференций является, как правило, низкая востребованность результатов, отсутствие практического внедрения предложений и наработок, отраженных в резолюции, в правотворческую и правоприменительную деятельность.

Далее остановимся конференциях с «усеченным уровнем научности». Признаки этих конференций:

${ }^{*}$ Считаем необходимым обратить внимание научной общественности на получившее в последнее время распространение дискриминационного понятия «конференция молодых ученых». Непонятно, что под этим подразумевается? Это возраст, неопытность, отсутствие весомых научных результатов, градация по возрасту? Это те конференции, в которых метрам от науки участвовать не совсем прилично? Тогда должны быть конференции для пожилых ученых, ученых среднего возраста и т.д. 
- заявленная тематика конференции столь широка, что к публикации принимаются материалы на любую тему; публикуемые материалы не рецензируются; большая часть материалов - низкого качества и подготовлена студентами, иногда начальных курсов. Например: «Реформирование правовой системы в контексте евроитеграционных процессов» - Сумской университет, «Правовое образование и правовая наука в Украине в условиях современных трансформационных процессов» Запорожский университет, «Инновационный потенциал и правовое обеспечение социально-экономического развития Украины: вызов глобального мира» - Полтавский институт экономики и права университета «Украина», «Правовая доктрина: международный опыт и практическая реализация в Украине» - Мариупольский университет;

- заявлено большое количество подгрупп и секций по различным направлениям, которые реально работать не будут из-за физического отсутствия участников;

- отсутствие научного потенциала в ВУЗе в области тематики конференции, отсутствие значимых практических результатов по предлагаемой тематике (научные работы, принятые и зарегистрированные законопроекты и т.д.). Причем «глобальную» тематику конференций зачастую заявляют периферийные и непрофильные университеты со слабым научно-юридическим потенциалом;

- издание материалов конференции. Материалы выступлений участников издаются в ограниченных экземплярах и только для «очень уважаемых участников». В библиотеки, даже крупнейшие, не направляются; в лучшем случае выкладываются на сайте учебного заведения, на украинском языке (без английской/русской аннотации) плохо читаемого учеными за пределами Украины;

- резолюция конференции «обо всем на свете» - никуда не направляемая, либо вообще отсутствующая;

- время проведения конференции - один рабочий день;

- цели проведения конференции: пиар-компания в средствах массовой информации; прием и встреча высокопоставленных чиновников МОН, народных депутатов, представителей местного самоуправления, дипломатов и других иностранных гостей - неформальное общение руководства ВУЗа с ними;

- приглашение научных работников не по наличию у них работ по тематике конференции, а по величине административных должностей;

- ограниченный бюджет (недостаток финансирования), попытка переложить большую часть расходов на кафедру и профессорско-преподавательский состав.

Нужны ли такие конференции? Наверное - да. Просто не нужно их называть научными. Эти конференции тоже выполняют поставленные задачи - пусть не научные, но актуальные для ВУЗов. Это будут просто конференции: студенческие, межотраслевые, исследовательские, представительские, профориентационные, юбилейные, имиджевые, коммуникативные, просветительские и т.д.

Учитывая вышеизложенное, для повышения эффективности и результативности научных конференций в области юриспруденции на наш взгляд необходимо:

- создание рабочего научно-аналитического органа, в функцию которого входил бы мониторинг научно-исследовательской деятельности в области права с целью сбора и анализа предложений по модернизации действующего законодательства и внедрению их в практическую законотворческую деятельность. Это может быть научноаналитическое подразделение при МОН Украины (Академии правовых наук, Верховной Раде), куда ученые-правоведы смогли бы отправлять свои наработки полученные при подготовке диссертационных исследований, научной деятельности, проведения конференций и т.д. по усовершенствованию действующей нормативной 
базы и перспективах развития законодательства. А этот орган, в свою очередь поддерживал бы связь с профильными комитетами главного законодательного органа государства и выступал лоббистом корректировки, дополнения и принятия новых законов. Либо же такую работу можно организовать в рамках действующего Института законодательства Верховной Рады Украины, который является базовым учреждением научно-правового обеспечения законодательной деятельности Верховной Рады Украины. Основными задачами Института являются подготовка предложений по формированию стратегии государственной правовой политики Верховной Рады Украины; разработка научных концепций развития национального законодательства; проведение сравнительных исследований законодательства Украины и законодательства иностранных государств. Кроме этого на институт возложена задача по подготовке проектов перспективных и текущих государственных программ законопроектных работ Верховной Рады Украины; организации мониторинга эффективности действующего законодательства Украины и прогнозирования последствий его применения; научного обоснования проектов законов по важнейшим вопросам развития общества и государства; проведение научной экспертизы проектов законодательных актов Украины и др.;;

- научные конференции по праву должны проводиться только под эгидою Академии правовых наук Украины, другие конференции - по усмотрению организаторов;

- разработки Академией правовых наук Украины единых требований к проведению научных конференций в области права; планирование конференций. Это дает возможность своевременного ознакомления научной общественности с тематикой проведения и планирования участия в них. Причем Академии правовых наук Украины должна анализировать и утверждать предложения ВУЗов о предлагаемых конференциях, с целью недопущения проведения однотипных конференций в разных ВУЗах, профанации конференциальной деятельности, проведение тематических конференций в ВУЗах со слабым научным потенциалом и т.д.

- как вариант создание под эгидою Академии правовых наук Украины единой электронной библиотеки материалов конференций.

\section{Список использованной литературы}

1. Балабан В.А. Научно-исследовательская работа и участие преподавателей вуза в научных конференциях // Известия Дальневосточного федерального университета. Экономика и управление. 2005. № 4. C. 125-130; Balaban V.A. Nauchno-issledovatelskaya rabota i uchastie prepodavatelej vuza v nauchnyh konferenciyah // Izvestiya Dalnevostochnogo federalnogo universiteta. Ekonomika i upravlenie. 2005. № 4. S. 125-130.

2. Глаголев М.В., Лапшина Е.Д. Методика расчета эффективности научной деятельности в научно-образовательном центре ДОСиГИК ЮГУ // Динамика окружающей среды и глобальные изменения климата. 2012. T. 3. № 2(6); Glagolev M.V., Lapshina E.D. Metodika rascheta effektivnosti nauchnoj deyatelnosti $v$ nauchnoobrazovatelnom centre DOSiGIK YuGU // Dinamika okruzhayushej sredy i globalnye izmeneniya klimata. 2012. T. 3. № 2(6).

3. Головецкий Н.Я., Мирошниченко Л. Н., Колесникова С. В. К вопросу о мониторинге эффективности деятельности образовательных организаций высшего образования // Интернет-журнал «НАУКОВЕДЕНИЕ» Том 7, №6 (2015) URL: http

* Официальный сайт института законодательства Верховной Рады Украины. Режим доступа http://instzak.rada.gov.ua/news/Pro_Instytut/Zagalna_inform/73074.html 
://naukovedenie.ru/PDF/23EVN615.pdf.; Goloveckij N.Ya., Miroshnichenko L. N., Kolesnikova S. V. K voprosu o monitoringe effektivnosti deyatelnosti obrazovatelnyh organizacij vysshego obrazovaniya // Internet-zhurnal «NAUKOVEDENIE» Tom 7, №6 (2015) URL: http ://naukovedenie.ru/PDF/23EVN615.pdf.

4. Дуденкова Т. А. Формальное и неформальное в научной коммуникации // Вестник Нижегородского университета им. Н. И. Лобачевского. Серия Социальные науки, 2010, № 3 (19), с. 128-134; Dudenkova T. A. Formalnoe i neformalnoe v nauchnoj kommunikacii // Vestnik Nizhegorodskogo universiteta im. N. I. Lobachevskogo. Seriya Socialnye nauki, 2010, № 3 (19), s. 128-134.

5. Ерёмченко О.А. Международные научные мероприятия как инструмент продвижения национальной науки // Экономика науки.2015. №4. С. 292-303; Eryomchenko O.A. Mezhdunarodnye nauchnye meropriyatiya kak instrument prodvizheniya nacionalnoj nauki // Ekonomika nauki.2015. №4. S. 292-303.

6. Королева Т.С., Васильев И.А., Торжков И.О. Критерии оценки эффективности деятельности научных учреждений // Труды Санкт-Петербургского научноисследовательского института лесного хозяйства. 2014. № 2. С. 94-111.; Koroleva T.S., Vasilev I.A., Torzhkov I.O. Kriterii ocenki effektivnosti deyatelnosti nauchnyh uchrezhdenij // Trudy Sankt-Peterburgskogo nauchno-issledovatelskogo instituta lesnogo hozyajstva. 2014. № 2. S. 94-111.

7. Павель Е.В., Банная Е.В. О результативности университетских научных конференций // Интернет-журнал «НАУКОВЕДЕНИЕ» Том 9, №6 (2017) https://naukovedenie.ru/PDF/21EVN617.pdf (доступ свободный); Pavel E.V., Bannaya E.V. O rezultativnosti universitetskih nauchnyh konferencij // Internet-zhurnal «NAUKOVEDENIE» Tom 9, №6 (2017) https://naukovedenie.ru/PDF/21EVN617.pdf (dostup svobodnyj).

8. Минатуллаев А.А., Хабибулаев Х.М. Проектный подход к организации и проведения студенческой научной конференции // УЭПС: управление, экономика, политика, социология, -2017. - № 4. - C.45-52; Minatullaev A.A., Habibulaev H.M. Proektnyj podhod k organizacii i provedeniya studencheskoj nauchnoj konferencii // UEPS: upravlenie, ekonomika, politika, sociologiya, -2017. - № 4. - S.45-52.

9. Кригер Г.С., Ахметзянова Р.Р., Ринская Н.В. Проведение студенческих конференций как одно из необходимых условий профессионального развития // История и педагогика естествознания, -2015. - № 4 - C.27-30; Kriger G.S., Ahmetzyanova R.R., Rinskaya N.V. Provedenie studencheskih konferencij kak odno iz neobhodimyh uslovij professionalnogo razvitiya // Istoriya i pedagogika estestvoznaniya, -2015. - № 4 - S.27-30.

10. Манухов В.Ф. Научная студенческая конференция как необходимый элемент подготовки бакалавров [Электронный ресурс] / В. Ф. Манухов, Н. Г. Ивлиева, А. Ф. Варфоломеев, С. А. Тесленок, О. И. Муженикова // Современные проблемы территориального развития : электрон. журн. -2018. - № 1. - 1 электрон. опт. диск (CDROM). - Систем. требования: Pentium III, процессор с тактовой частотой 800 МГц ; 128 Мб ; 10 Мб ; Windows XP/Vista/7/8/10; Acrobat 6x; Manuhov V.F. Nauchnaya studencheskaya konferenciya kak neobhodimyj element podgotovki bakalavrov [Elektronnyj resurs] / V. F. Manuhov, N. G. Ivlieva, A. F. Varfolomeev, S. A. Teslenok, O. I. Muzhenikova // Sovremennye problemy territorialnogo razvitiya : elektron. zhurn. -2018. - № 1. - 1 elektron. opt. disk (CD-ROM). - Sistem. trebovaniya: Pentium III, processor s taktovoj chastotoj $800 \mathrm{MGc} ; 128 \mathrm{Mb} ; 10 \mathrm{Mb}$; Windows XP/Vista/7/8/10; Acrobat 6h.

11. Ларичев О.И., Мечитов А.И. Многофакторный анализ конференций Международного института прикладного системного анализа // Управление и научнотехнический прогресс / Под ред. Б. 3. Мильнера. - Достижения и перспективы. Выпуск 
16 № 3. М.: Международный центр научно -технической информации, 1981. - С. 53-58; Larichev O.I., Mechitov A.I. Mnogofaktornyj analiz konferencij Mezhdunarodnogo instituta prikladnogo sistemnogo analiza // Upravlenie i nauchno-tehnicheskij progress / Pod red. B. Z. Milnera. - Dostizheniya i perspektivy. Vypusk 16 № 3. M.: Mezhdunarodnyj centr nauchno tehnicheskoj informacii, 1981. - S. 53-58.

\section{Н. Л. Шелухін}

\section{ПРО НАУКОВІ КОНФЕРЕНЦІЇ В ГАЛУЗІ ПРАВА І НЕ ТІЛЬКИ}

У статті розглядаються питання проведення наукових конферениій в області юриспрудениії. Розглядається класифікація наукових конференцій, основні иілі їх проведення, виділяються основні етапи їх проведення. Звертається увага на проведення псевдонаукових конферениій, наводяться $i$ розкриваються їх ознаки. Вносяться пропозиції про уніфікацію вимог до проведення наукових конферениій, а так само їх проведення тільки під егідою Академії юридичних наук України.

Ключові слова: наукова конференція, класифікація конференцій, иілі $i$ завдання конференцій, Академія правових наук України, псевдонаукові конференції, єдина електронна бібліотека матеріалів конференцій.

\section{N. Shelukhin}

\section{ON SCIENTIFIC CONFERENCE IN THE FIELD OF LAW AND NOT ONLY}

The article discusses the issues of conducting scientific conferences in the field of jurisprudence. We consider the classification of scientific conferences, the main objectives of their conduct, highlights the main stages of their conduct. Attention is drawn to pseudoscientific conferences, their signs are presented and disclosed. Proposals are being made on the unification of requirements for holding scientific conferences, as well as their holding only under the auspices of the Academy of Legal Sciences of Ukraine

Key words: scientific conference, classification of conferences, goals and objectives of conferences, Academy of Legal Sciences of Ukraine, pseudoscientific conferences, a single electronic library of conference materials.

Стаття надійшла до редакції 12.05.2019 р.

УДК 346.1

\section{С. О. Алєксеєв}

\section{ТЕОРЕТИЧНІ ПІДХОДИ ДО ВИЗНАЧЕННЯ НОРМ МІЖНАРОДНОГО ПРАВА, ЩО РЕГЛАМЕНТУЮТЬ СУДОЧИНСТВО В ГОСПОДАРСЬКИХ СУДАХ УКРАЇНИ}

В умовах глобалізачії світового господарства об'єктивуються та актуалізуються питання участі національних економік в системі міжнародного економічного співробітництва. Але така участь здійснюється у своєрідному вигляді, управлінський алгоритм якого досить яскраво проявляється через надбання геоекономічної науки.

Ключові слова: господарське право, судочинство, міжнародні стандарти.

DOI 10.34079/2226-3047-2019-9-17-79-92 